\title{
Tool Wear Analysis During Turning of Hard Material by Simulink
}

\author{
Rahul Kshetri, Ajay, Shivasheesh Kaushik, Vinay Sati
}

\begin{abstract}
Present work is an attempt to develop a simulink model of tool wear by machining of Bearing Steel (62 HRC) using cubic boron nitride $(\mathrm{CBN})$ tool. The available mathematical model in the scholarly literature is used to make the simulation model using MATLAB software. Three components of tool wear adhesive wear, abrasive wear \& diffusion wear are considered separately for their modeling and later modeling of total wear is done. Variation of tool wear is studied with respect to cutting speed. The developed simulink model is capable to do the similar type of study by changing the workpiece and tool material combination.
\end{abstract}

Keywords: Simulink, Tool wear, Mathematical modeling, Turning.

\section{INTRODUCTION}

To define the general wear rate or volume loss, for distinct wear mechanisms various models have been proposed. And that includes their applications during metal cutting. Such eminent work are being reported as on abrasive wear [1,2] on diffusive wear [4-5] and on adhesive wear [3-4]. Generally, during the cutting operation wear takes place on tool due to diffusion, abrasion and adhesion and, its root cause boost in temperature and distribution of stress on tool $[6,7,8]$. The main objective of this work is to develop a mechanistic model to anticipate rate of tool wear, during cutting operation. This study strives to find a model that describes the process of wearing at a mechanism level. It would be desirable to have such a model that shows how much different mechanisms acts on the tool. A good wear model would make it possible to cut down the amount of testing needed when developing new tools, and increase the level of understanding for the wear process. At the end the evolved new tools may occur much faster and result in more wear resistive tools.

In case of modeling at the beginning the mathematical model is developed and then it has been transformed to simulink model, the process is shown in "Fig $.2 "$. All model and their classification is shown in "Fig.1".

Revised Version Manuscript Received on Jun 20, 2019.

Rahul Kshetri, Department of Industrial and production engineering, G.B.P.U.A.T Pantnagar ,U.S Nagar,

Ajay, Department of Industrial and production engineering, G.B.P.U.A.T Pantnagar, U.S Nagar, India,

Shivasheesh Kaushik, Department of Mechanical Engineering, Shivalik College of Engineering, Dehradun, India
Vinay Sati, Department of Mechanical Engineering, Amrapali Institute of Technology and Applied Science, Haldwani, India

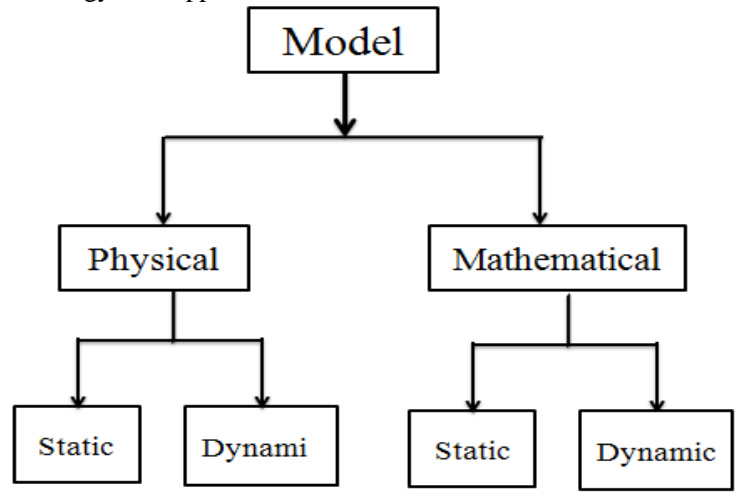

Fig.1 Classification of models

\section{STEPS OF MODELING AND SIMULATION}

Steps of mathematical modeling have been clearly shown in Fig.2. Initially one has to identify the real world problem by focusing on the background of research on workable problem. After simplifying the real world problem working model is formulated into mathematical terms. Working model in mathematical terms is known as mathematical model, Mathematical model is converted in to suitable computational model by using computational tool. Computational tool includes different software's like $\mathrm{C}, \mathrm{C}++, \mathrm{JAVA}$,MATLAB etc. In the present work MATLAB is used as a computational tool, after simulation results are presented in the forms of graphs. Conclusions are drawn by combining all results.

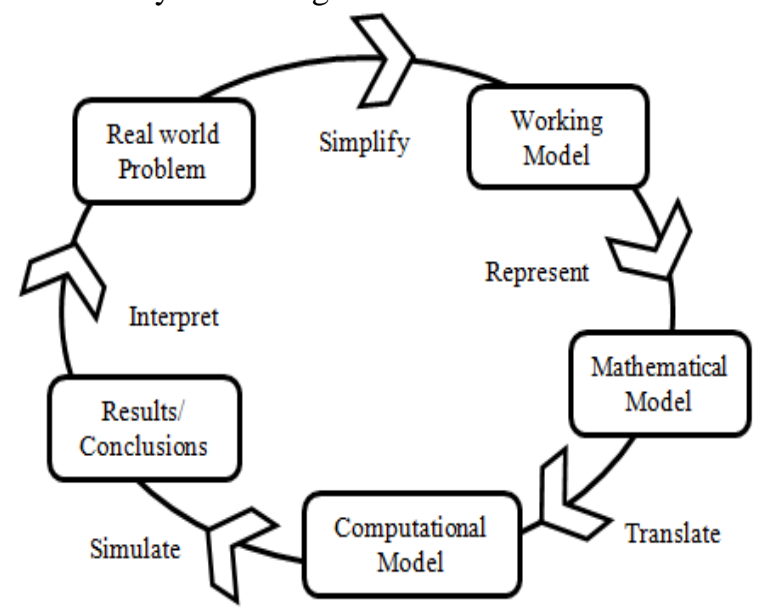

Fig.2 Development of Mathematical modeling Process 


\section{DIFFERENT TYPE OF WEAR}

Different types of wear depending on its mechanism are described below.

\section{Abrasive}

This is a phenomenon in which, hard particles abrade on softer material throughout the surface. In which relative velocity would be take place, and confide on hardness (relative) of abrading particles and abraded material [9]

\section{Adhesive}

This phenomenon occurs under high temperature and pressure, when two materials are acting their forced together, and in relative motion. Small particles get welded together causing failure of one metallic object.[10]

\section{Diffusion}

Phenomenon in which atoms of one material diffuse over to another. That happens due to high feed rate and cutting speed. It is suppose that, diffusion causes the tool to be diminish of its atoms culpable for its hardness, and diffusion becoming more prudent for abrasive and adhesive wear.

\section{A. DeVElopment of Mathematical Model (Volume CHANGE) \\ It contains two steps}

(i ) Derivation of function of volume change in time

(ii) Derivation of geometric volume change

The total volume of tool material removed is the summation of all three (abrasive, adhesive and diffusive) wear models are given below.

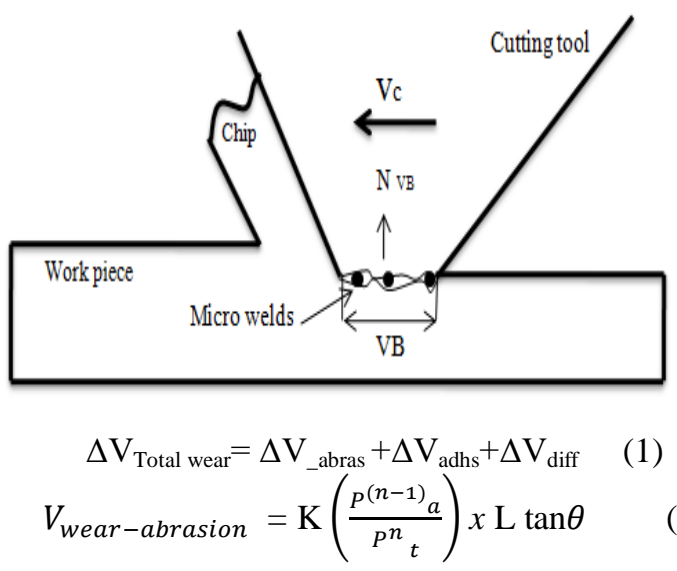

When tool cuts unwanted material from the workpiece, interaction are shown in "Fig .3" after cover distance $\mathrm{x}$ length of flank wear is VB other notations of "equation (2)" are given below.

$[\mathrm{L}=$ Load between surfaces, $\mathrm{w}=$ width of cutting, $\mathrm{Vc}=$ Cutting velocity, $\mathrm{Pa}=$ Hardness (abrasive particles), $\mathrm{P}_{\mathrm{t}}$ Hardness (tool), $\sigma=$ Normal stress (flank area), VB = flank wear length, $\theta=$ angle(friction)

$$
P_{t} / P_{a}<0.80 ; \mathrm{n}=1.0, \mathrm{~K}=0.333 \text {, }
$$$$
0.8<P_{t} / P_{a}<1.25 ; \mathrm{n}=3.445, \mathrm{~K}=0.189
$$

$$
\text { otherwise } \quad \mathrm{n}=7.0, \mathrm{~K}=0.46
$$

$$
V_{\text {wear-abrasion }}=K_{\text {abrasion }} \mathrm{K}
$$

$$
\left(\frac{P^{(n-1)} a}{P^{n}}\right) V_{C} w V B \sigma \Delta t
$$

\section{Adhesive wear}

$$
V_{\text {wear-adhesion }}=K_{\text {adhesion }} e^{a T} V_{C} w \sigma \Delta t
$$

Diffusive wear

$$
V_{\text {wear }- \text { diff }}=K_{\text {diff }} \sqrt{V_{C} V B} e^{-\left(K_{Q} / T+273\right)} \mathrm{w} \Delta t
$$

Total volume change is the sum of volume change by abrasive adhesive and diffusive wear and the whole change of volume are obtaining after add on "equation (3), (4) and (5)" and the ultimately given below.

$$
\begin{gathered}
\Delta \mathrm{V}_{\text {Total wear }}=\Delta \mathrm{V}_{\text {abras }}+\Delta \mathrm{V}_{\text {adhs }}+\Delta \mathrm{V}_{\text {diff }} \\
{\left[\begin{array}{c}
K_{\text {abrasion }} \cdot K \cdot\left(\frac{P^{(n-1)} a}{P^{n}}\right) V_{C} \cdot V B \cdot \sigma+ \\
K_{\text {adhesion }} \cdot e^{a T} \cdot V_{C} \cdot \sigma+ \\
K_{\text {diff }} \sqrt{V_{C} V B} e^{-\left(K_{Q} / T+273\right)}
\end{array}\right] \mathrm{w} \Delta t}
\end{gathered}
$$

\section{GEOMETRIC DEFINITION OF WEAR VOLUME ON FLANK}

According to "Fig.4" it has been observed that dVB is the final increment in VB (flank wear), when the insert loose the height (ds).(dVB1) is the loss or increases of VB caused by the rake angle $(\gamma)$, and (dVB2) is the increase of VB, caused by the relief angle $(\alpha)$.

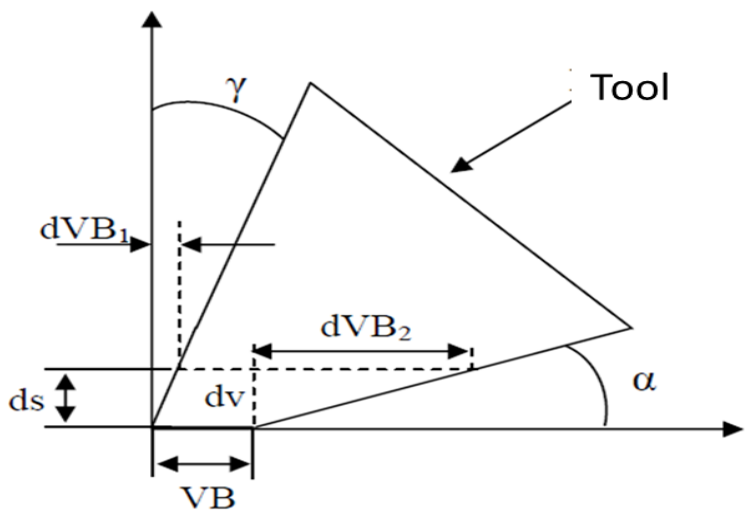

Fig. 4 volume loss for insert that grow the flank wear length ( dVB)

$d V B=d V_{2}-d V B_{1}$

After put down the value of "equation (10)" in to "equation (6)" the final wear model is represented by "equation (11)".

$$
\mathrm{dv}=\mathrm{w} \cdot \mathrm{ds} \cdot\left(\mathrm{VB}+\frac{\mathrm{dVB}}{2}\right)
$$




$$
\begin{aligned}
& d s=d V B\left(\frac{\tan \alpha}{1-\tan \alpha \cdot \tan \gamma}\right) \\
& d v=w \cdot V B \cdot d V B \cdot\left(\frac{\tan \alpha}{1-\tan \alpha \cdot \tan \gamma}\right)
\end{aligned}
$$

$$
\begin{aligned}
& \frac{d V B}{d t}=\frac{d V B}{d t}= \\
& \left(\frac{1-\tan \alpha \cdot \tan \gamma}{V B \cdot \tan \alpha}\right)\left[\begin{array}{r}
K_{\text {abrasion }} \cdot K \cdot\left(\frac{P^{(n-1)} a}{P^{n}}\right) V_{C} \cdot V B \cdot \sigma \\
+K_{\text {adhesion }} \cdot e^{a T} \cdot V_{C} \cdot \sigma+ \\
K_{\text {diff }} \sqrt{V_{C} V B} e^{-\left(K_{Q} / T+273\right)}
\end{array}\right.
\end{aligned}
$$

\begin{tabular}{|c|c|c|}
\hline M aterial pr & $\begin{array}{l}\text { erties( tool and v } \\
\text { Workpiece } \\
52100 \text { Bearing } \\
\text { steel } \\
\text { (62 HRC) }\end{array}$ & $\begin{array}{l}\text { piece) } \\
\text { Tool } \\
\text { CBN }\end{array}$ \\
\hline $\begin{array}{l}\text { Density } \\
\left(\mathrm{kg} / \mathrm{m}^{3}\right)\end{array}$ & 4370.1 & 7800 \\
\hline $\begin{array}{l}\text { Thermal } \\
\text { conductivity } \\
(\mathrm{W} / \mathrm{m}-\mathrm{K})\end{array}$ & 44 & 46.6 \\
\hline $\begin{array}{c}\text { Specific heat } \\
\text { capacity } \\
(\mathrm{J} / \mathrm{Kg} \mathrm{K})\end{array}$ & 750 & 475 \\
\hline $\begin{array}{l}\text { Hardness } \\
\left(\mathrm{Kg} / \mathrm{mm}^{2}\right)\end{array}$ & 150 & 2800 \\
\hline
\end{tabular}

Table.1

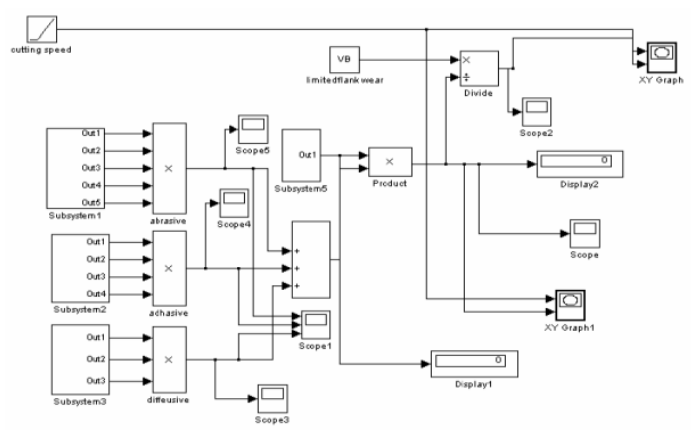

Fig.5 Main simulink model

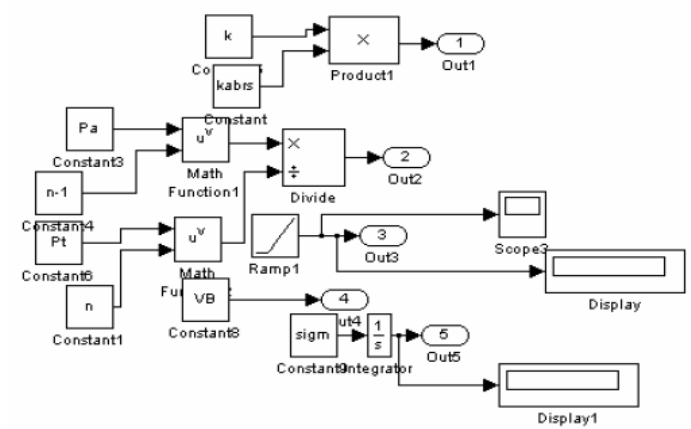

Fig.6 Sub system.1

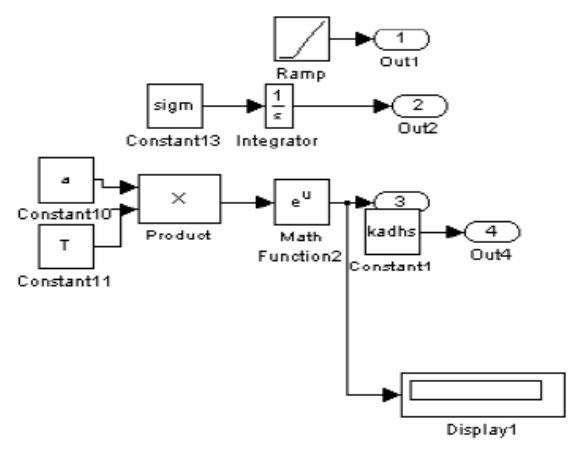

Fig.7 Subsystem .2

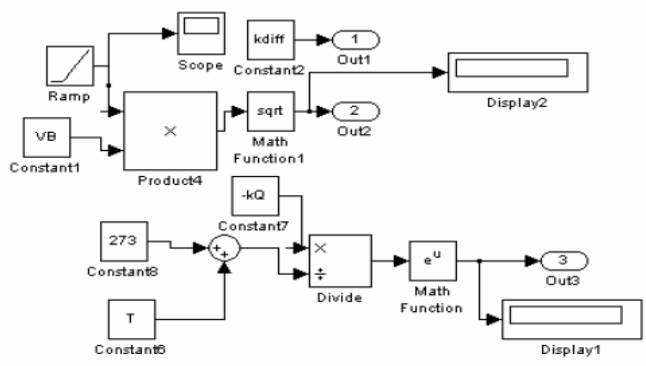

Fig.8 Sub system .3

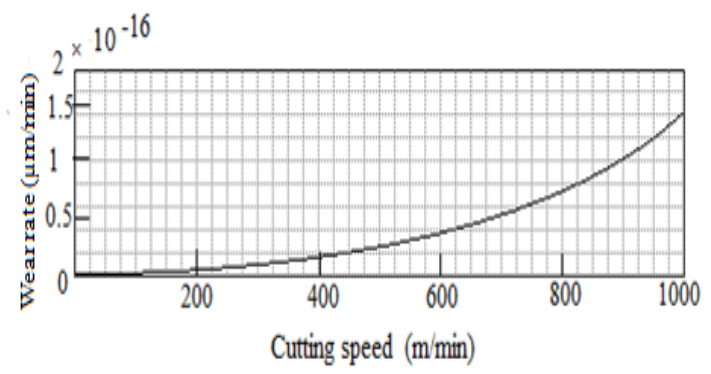

Fig.9 Abrasive tool wear rate with cutting speed

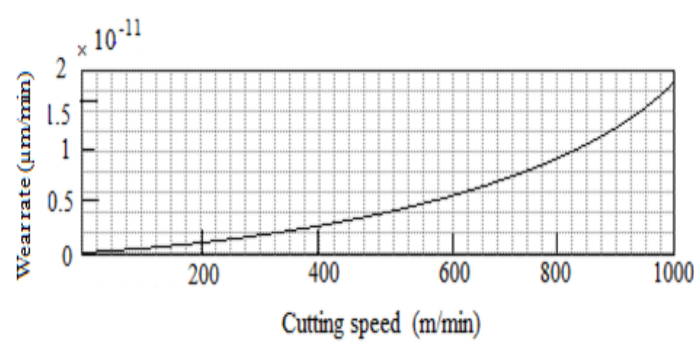

Fig.10 Adhesive tool wear rate with cutting speed

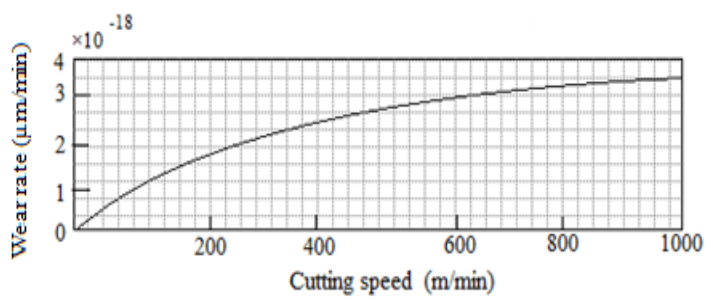

Fig.11 Diffusive wear rate witcutting speed 


\section{SIMULINK MODEL FOR TOOL WEAR ESTIMATION}

Simulink is a tool of MATLAB for simulating dynamic systems. Final wear model can express as a flow chart of simulink by making connections of different operators. With the help of similink all the results occurs with respect to time .The modeling of presented wear model is like that the graphs have been occurred in between rate of wear with respect to cutting speed. Main simulink model have been clearly shown in Fig.5 .We can put all the output values of sub system 1, 2 and 3 as an input for the main simulink model. All sub simulink models have been clearly shown in Fig 6, 7 and 8

Values can find out with the help of simulation or by experiment. All the values given below have been calibrated by the experiment according to reference [12] and all value are given below.

$\mathrm{K}_{\mathrm{abr}}=0.13 * 10{ }^{6}, \mathrm{~K}_{\text {diff }}=1 * \mathrm{E}-24, \mathrm{~K}_{\mathrm{adh}}=1.8383 * \mathrm{E}-14, \mathrm{a}=$ $9 * \mathrm{E}-4, \mathrm{~K}_{\mathrm{Q}}=20000$

Other mechanical properties (wok piece and tool) are disposed in Table. 1 .After put down all these value to the main model and their sub models results of simulink model have been clearly shown in Fig.9, 10 and 11 for abrasive, adhesive and diffusive model.

\section{CONCLUSIONS}

According to presented simulink model one can find out tool wear rate for any cutting speed with different combination of tool and workpiece. Results show that wear of tool is increasing with cutting speed. At maximum speed the value of adhesive tool wear is maximum is near about in order $2 * 10^{-11} \mu \mathrm{m}$ where as diffusive wear is bearing steel and cubic boron nitride work tool combination. Initial wear rate due to abrasion and adhesion are found lower by their value as compared to diffusion wear. According to results it has been observed that diffusive wear rate increasing tremendously with increasing cutting speed and after some time the wear rate is found constant whereas abrasive and adhesive tool wear rate increases tremendously during machining.

\section{REFERENCES}

1. Rabinowicz, E., Dunn, L. A., and Russell, P. G., 1961, “A Study of Abrasive Wear under Three-Body Conditions,' Wear, 4, pp. 345355.

2. Williams, J. A., 1994, Engineering Tribology, Oxford University Press, NY

3. Archard, J. F., 1953, “Contact and Rubbing of Flat Surfaces,' J. Appl. Phys., 24, pp. 981-988.Wear of Carbide Tool,'” ASME J. Eng. Ind., 100 , pp. 236-243.

4. Kannatey-Asibu, E., Jr., 1985, “A Transport-diffusion Equation in Metal Cutting and Its Application to Analysis of the Rate of Flank Wear,' ASME J. Eng. Ind., 107, pp. 81-89.

5. Loladze, T. N., 1981, "'Of the Theory of Diffusion Wear,' CIRP Ann., 30 1!, pp. 71-76.

6. Usui, E., Shirakashi, T., and Kitagawa, T., 1978, "Analytical Prediction of Three Dimensional Cutting Process, Part 3: Cutting Temperature and Crater

7. Kramer, B. M., and Judd, P. K., 1985, "Computational Design of Wear Coating,'’ J. Vac. Sci. Technol. A, A3 6!, pp. 2439-2444.

8. Kramer, B. M., 1986, "Predicted Wear Resistances of Binary Carbide Coatings,'” J. Vac. Sci. Technol. A, A4 6!, pp. 2870-2873.

9. Mamalis, A. G., J. Kundrak and M. Horvath, 2002. "Wear and Tool Life of CBN CuttingTools". International Journal Advance Manufacturing Technology 20:475-479.
10. Rabinowicz, E., 1977. "Abrasive wear resistance as a materials test", Lubrication Engineering, Vol. 33, pp.378-381

11. Kannatey, 1985. "A Transport-diffusion Equation in Metal Cutting and Its Application to Analysis of the Rate of Flank Wear", ASME J. Eng. Ind., 107, pp. 81-89.

12. Huang, Yong, and Steven Y. Liang. "Modeling of CBN tool flank wear progression in finish hard turning." TRANSACTIONSAMERICAN SOCIETY OF MECHANICAL ENGINEERS JOURNAL OF MANUFACTURING SCIENCE AND ENGINEERING 126.1 (2004): 98-106.

13. Mathworks, Matlab User manual

\section{AUTHORS PROFILE}

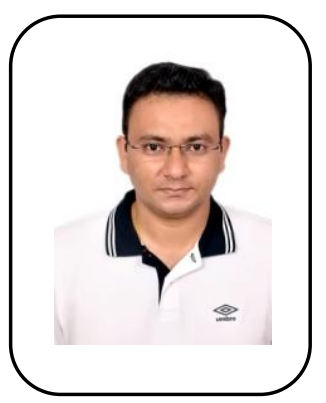

Dr. Rahul Kshetri ${ }^{1}$, had complete their Bachelor degree from Govind Ballabh Pant Engineering College, Pauri Garhwal with the specialization of Production Engineering (Mechanical), also earned his master's (Manufacturing Engineering and Management) and Ph.D. from Department of Industrial and Production Engineering, G.B.P.U.A.T Pantnagar, U.S Nagar. Research work specialization of author is in the field of modeling of turning operation with published national and international paper and conferences. Author also has published books based on capacitive transducer in LabVIEW environment and quality function deployment in fuzzy AHP. Author currently working as Assistant Professor, Shivalik College of Engineering,Dehradun.

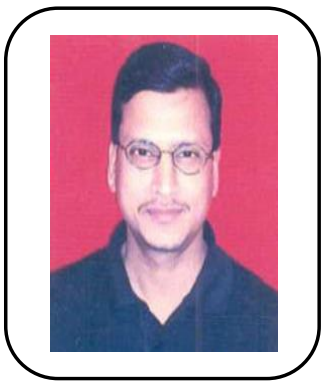

LabVIEW environment
Dr. Ajay, ${ }^{1}$, working as professor, Department of Industrial \& Production Engineering, G.B.P.U.A.T Pantnagar, he has done Ph.D. from N.I.T.Kurukshetra with specialization in Management of Technology and M.E. from University of Roorkee in Production and Industrial System Engineering, with published national and international papers and conferences. Author guided M.Tech and Ph.D scholars and also published books based on workshop technology and capacitive transducer in

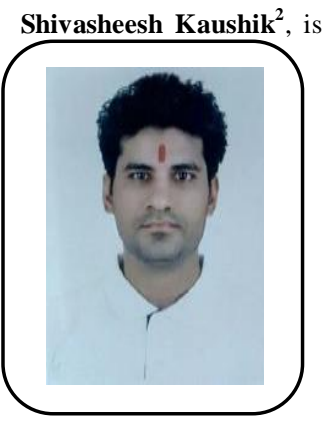

an Assistant Professor at Shivalik College of Engineering, Dehradun, India. He received his M.Tech. from B.T.K.I.T formerly known as K.E.C, Dwarahat in 2015, India. Presently, he has research interest in Bio fuels pressure vessels and piping, plates and shells, composite materials and thermal analysis. He is life Associate Member (Membership Number: AM1840951) in IEI organization and Certified Charted Engineer from IEI Organization. He has 5 to 8 publications in international and national journals and conferences. He has filed two patents

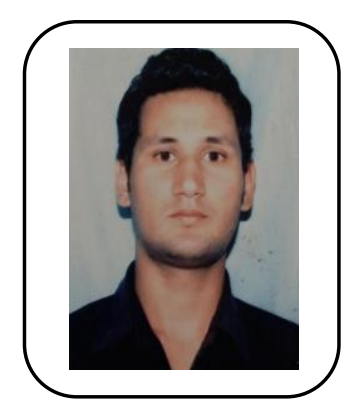

Vinay Sati ${ }^{2}$, is an Assistant Professor at Amrapali Group Of Institute, Haldwani. He received his M.Tech. from B.T.K.I.T formerly known as K.E.C, Dwarahat in 2015, India. Presently. He has research interest in Bio fuels, Boiler efficiency, Fluid flow and thermal analysis. He has 5 to 8 publications in international and national journals and conferences. He has filed two patents. 